Int. J. Electrochem. Sci., 15 (2020) $4406-4420$

\title{
Effect of pH on the Passive Film Characteristics of Lean Duplex Stainless Steel in Chloride-Containing Synthetic Tap Water
}

\author{
Sangwon Cho ${ }^{1}$, Jeong-Hun An ${ }^{1}$, Seung-Hwan Lee ${ }^{2}$, Jung-Gu Kim ${ }^{1, *}$ \\ ${ }^{1}$ Department of Materials Science and Engineering, Sungkyunkwan University, 2066, Seobu-Ro, \\ Jangan-Gu, Suwon-Si, Republic of Korea, 16419 \\ ${ }^{2}$ Steel Solution Marketing Dept., POSCO Global R\&D Center, 100, Songdogwahak-Ro, Yeonsu-Gu, \\ Incheon, Republic of Korea, 21985. \\ *E-mail: kimjg@ @kku.edu
}

doi: $10.20964 / 2020.05 .32$

Received: 25 October 2019 / Accepted: 18 December 2019 / Published: 10 April 2020

The localized corrosion properties of lean duplex stainless steel and 316L stainless steel were compared using electrochemical testing and angle resolved X-ray photoelectron spectroscopy analysis. Electrochemical testing at $\mathrm{pH} 7$ revealed that the pitting corrosion resistance of LDSS was superior to that of $316 \mathrm{~L}$, but the crevice corrosion resistance of $316 \mathrm{~L}$ was better than that of LDSS. In potentiodynamic polarization testing, as the $\mathrm{pH}$ decreased, the pitting potential of $316 \mathrm{~L}$ did not change significantly. However, the pitting potential of LDSS sharply decreased with decreasing $\mathrm{pH}$, and was lower than that of $316 \mathrm{~L}$ at $\mathrm{pH} 2$. Electrochemical impedance spectroscopy results confirmed that the passive film of 316L is more stable than that of LDSS at lower $\mathrm{pH}$. Regardless of the $\mathrm{pH}$ and film depth, the passive film compositions of 316L and LDSS were similar, except for Mo compounds. Mo peaks were not detected in either steel at $\mathrm{pH} 7$, but pronounced spectra of the Mo were detected only for the 316L steel at $\mathrm{pH}$ 2. Mo oxides are not formed at a neutral $\mathrm{pH}$, but formed at lower $\mathrm{pH}$. The improved resistance to crevice corrosion of 316L resulted from the formation of the Mo-enriched passive film at low $\mathrm{pH}$.

Keywords Lean duplex stainless steel, Pitting corrosion, Crevice corrosion, Passive film, ARXPS

\section{FULL TEXT}

(C) 2020 The Authors. Published by ESG (www.electrochemsci.org). This article is an open access article distributed under the terms and conditions of the Creative Commons Attribution license (http://creativecommons.org/licenses/by/4.0/). 